The second volume now shows the work of the second year to be devoted to heat, heat engines and electrotechnics. The scope is thus kept within somewhat narrower bounds, but the treatment goes deeper and, being direct and practical, should make an appeal to both students and their teachers.

The main principles have been stated clearly and succinctly, and the approach to the subject is largely by experiment and deduction. The course outlined is a progressive one and provides a good preparation and basis for the more specialized studies which have to follow, and the student will get considerable help from the numerous illustrations of machinery and apparatus which have been supplied by their makers.

(3) In the preparation of "Engineering Mechanics" by Fairman and Cutshall, the authors have adopted quite a different method of overcoming the difficulty of keeping within the available facilities for study. Appreciating that in institutions where time is limited by the requirements of other subjects in the curriculum a full basic course cannot be attempted, they have eliminated those portions which must, in any event, be dealt with in more specialized classes and may therefore be deferred until later. They hold that a task is more easily accomplished if all the tools are available, and therefore, at each stage, make careful preparation for it by setting out and explaining clearly the methods, conditions, and the fundamental laws of physics applicable.

The course is one of general mechanics as applied to engineering, and includes statics, dynamics, friction, energy, balancing, impulse, impact and gyroscopic action. It is intended for students who have had a training in mathematics up to the integral calculus, and for such as have this preparation it offers a clearly stated exposition of the subject with a discreet mixture of problems of the practical and the academic types.

\title{
Modes of Thought
}

\section{Modes of Thought}

By Prof. Alfred North Whitehead. Pp. $x+241$. (Cambridge: At the University Press, 1938.) $7 s .6 d$. net.

PRoF. A. N. WHITEHEAD'S latest book consists of eight lectures and a short address as epilogue. Two of the lectures have been published before under the title "Nature and Life". Any reader who is unfamiliar with the author's philosophy would be well advised to begin with the first of these (Lecture VII). Prof. Whitehead points out there that according to the traditional doctrine of science, which has been taken over by common sense, Nature consists of permanent things, bits of matter, moving about in a space which is otherwise empty. The connexions between such bits of matter are purely spatial, and therefore motion is the only mode of change. Modern physical theory contradicts everything this doctrine asserts, nevertheless it remains as a general presupposition.

The result is a complete muddle in thought, yet any theory which does not presuppose the traditional view seems paradoxical. The traditional view, it is argued, is not merely inconvenient, but definitely self-contradictory. The only final real fact admitted by it is "this bit of matter occupying this region of space at this durationless instant", without reference to any other instant or any other piece of matter or to any other part of space. But what are we to make of velocity, acceleration or momentum at an instant? These notions are necessary for physics, and yet are without meaning on the traditional view. For the modern view, process, activity and change must be taken as primary matter of fact. At an instant there is nothing. Each instant is only a way of grouping matters of fact by taking a cross-section through them. All interrelations of matters of fact must involve transition. Each concrete fact is the consequence of a process of 'concrescence' from other facts. In its turn it gives way to contribute to the concrescence of others. A thing becomes real by being involved in the "creative advance of nature". The notion of creative advance is the starting-point of Prof. Whitehead's theory.

The rest of the book is concerned with the development of certain aspects of this fundamental notion. The treatment is useful and illuminating for anyone who already knows something of his views. To anyone not so prepared a good deal of it may be puzzling. The author's mode of expression, though often most happy and usually clear, is sometimes elusive. Unfortunately the opening pages are of this character, and might frighten off an unwary reader.

It is interesting and cheering to find Prof. Whitehead, who cannot be accused of ignorance of mathematical logic, combating the fashionable doctrine that arithmetical propositions are all tautological. The doctrine has been propagated with the help of such a terrifying array of technicalities that scarcely anyone has dared to protest against it.
A. D. Ritchie. 